\title{
A COMPAIXÃO EM TEMPOS DE PANDEMIA: um diagnóstico do presente à
}

\author{
luz de Foucault e Nietzsche
}

\author{
Compassion in pandemic times: a diagnosis of the present in the light of foucault and \\ nietzsche
}

Vilmar Prata ${ }^{1}$

\begin{abstract}
RESUMO: Em tempos de crise, e agora, em tempos de pandemia, a melhor solução seria a compaixão? O objetivo dessa reflexão é lançar um olhar à luz de Foucault e Nietzsche para a compaixão, não como meio de controle ou o fim de determinada crise, mas um olhar sobre as transformações sociais e pessoais que ela provoca e que vão além dos lugares e corpos. Foucault nos lembra que desde os gregos, a soberania de si acontece na medida em que o sujeito lança um olhar para a própria vida, num gesto de autoconhecimento. Porém, ele não nos deixa esquecer que não podemos ignorar o outro, pois a vida voltada a si e movida pela sabedoria nos remete à relação com o outro. Portanto, voltar-se para o outro faz parte do movimento de ser soberano de si, que é em vias de regra, estar para o outro, atento às suas necessidades enquanto sujeito que traz em si os questionamentos sobre a vida que também existem em nós. E nessa realidade nos deparamos com o desdobramento do pensamento de Nietzsche que, em contrapartida, vê a compaixão ao longo de sua obra, como um gesto egoísta, que visa tão somente o próprio gozo, a partir de uma postura soberana em relação ao outro, dissimulando a própria impotência diante de sua condição humana e inacabada. Dessa maneira, como poderíamos compreender a compaixão a partir de Foucault e Nietzsche, para um possível diagnóstico do nosso presente?

Palavras-chave: Compaixão. Foucault. Nietzsche.
\end{abstract}

ABSTRACT: In times of crisis, and now, in times of pandemic, would the best solution be compassion? The purpose of this reflection is to take a look in the light of Foucault and Nietzsche for compassion not as a means of control or the end of a given crisis, but a look at the social and personal transformations that it causes and that goes beyond places and bodies. Foucault reminds us that since the Greeks the sovereignty of self happens as the subject looks at his own life, in a gesture of self-knowledge. However, he does not let us forget that we cannot ignore the other, because life turned to itself and moved by wisdom, leads us to the relationship with the other. Therefore, turning to the other is part of the movement of being sovereign of oneself, which is, in general, being for the other, attentive to their needs as a subject that brings with them questions about life that also exist in us. And in this reality we are faced with the unfolding of Nietzsche's thought, which, on the other hand, sees compassion throughout his work, as a selfish gesture, which aims only at his own, enjoyment, from a sovereign stance towards the other, concealing his

\footnotetext{
${ }^{1}$ Doutorando em Filosofia pela Universidade Federal de Sergipe - UFS, Mestre em Memória, Linguagem e Sociedade pela Universidade Estadual do Sudoeste da Bahia -UESB (2017). Estágio sanduíche em filosofia na Sorbonne Nouvelle Paris III (2015) sob orientação de Philippe Dubois. Estágio sanduíche na Faculdade de Filosofia, Ciências e Letras da USP - Ribeirão Preto (2016) sob orientação de Leda Verdianni Tifoune. Pós -graduado lato sensu em Filosofia e Existência pela UCB - Universidade Católica de Brasília (2012). Graduado em Filosofia pela Faculdade Batista Brasileira (2010). Membro do grupo de pesquisa Ética e Psicologia Moral na Filosofia Antiga - UFBA. Membro do Viva Vox, grupo de pesquisa em Filosofia Antiga - UFS e membro do grupo nacional - Pórtico de Epicteto. Tem experiência na área de Filosofia e Análise do discurso, com ênfase em Ética, filosofia antiga e contemporânea, atuando principalmente nos seguintes temas: Teoria da Memória, Teoria do Conhecimento, Linguagem, Governamentalidade, Ética, Sujeito, Subjetividade, Verdade, estoicismo, Michel Foucault, Sêneca. Atuou como professor de Ética e Introdução à Filosofia na FAECO (2015) e professor visitante de Introdução à Filosofia no IEED (2010). Membro do grupo editorial dos periódicos REDISCO (2015-2017) e O CORPO É DISCURSO (2015-2017) atuando principalmente como revisor. E-mail: vilmarlabedisco@gmail.com
} 
own helplessness in the face of his unfinished human condition. In this way, how could we understand compassion from Foucault and Nietzsche, for a possible diagnosis of our present?

Key-words: Compassion. Foucault. Nietzsche

\section{INTRODUÇÃO}

Em tempos de crise, em tempos de qualquer tipo de crise social ou individual e, agora, mais especificamente, em tempos de crise gerada por uma pandemia, a melhor atitude seria a da compaixão? E se for, quais efeitos a compaixão por si e pelo outro, seja este outro familiar, próximo a nós, seja o outro anônimo que se encontra em tantos lugares e corpos, poderia causar? O objetivo dessa reflexão é lançar um olhar à luz de Foucault e Nietzsche para o gesto de compaixão presente nas relações humanas quando se instaura uma situação de caos, ameaçando a vida, ou as vidas dos sujeitos que compõem determinado momento crítico e delicado da história, exigindo de todos os envolvidos, direta ou indiretamente, apenas pelo fato de tomar consciência de determinada situação, um posicionamento diante de si e do outro, seja de comprometimento autêntico que reverbera em atitudes concretas frente à dor do outro, ou o comprometimento vazio de ação, seja uma posição de indiferença ou mesmo de um comprometimento narcisista.

Nesse viés, proponho uma breve reflexão sobre a compaixão nesses tempos difíceis que vivemos, não tanto tomando-a como uma possibilidade de salvação, controle do caos ou o fim de determinada crise, mas sugerindo um olhar questionador sobre as transformações sociais e pessoais que, tanto a compaixão como a crise, num movimento de mão dupla, podem vir a provocar, indo muito além dos espaços geográficos e das posições sociais que os corpos dos sujeitos ocupam na sociedade. Pois bem, diante do sofrimento causado por alguma catástrofe natural, por alguma ação negativa do homem sobre sua própria vida ou sobre a vida do outro, como algum tipo de violência física ou emocional, geralmente, diante de um cenário caótico estabelecido, é possível encontrar quatro tipos de comprometimento do sujeito:

1. Começo apontando aquelas e aqueles que simplesmente se posicionam alheios à dor do outro, incapazes de sentir empatia pelo sofrimento que supostamente não lhes pertencem, ignoram completamente a gravidade da situação, seja por fuga, seja mesmo como um mecanismo de defesa, e, indiferentes seguem suas vidas, se, óbvio, não forem afetados diretamente pelo problema em questão. De toda forma, indiretamente, todos são afetados, uns em grau maior ou menor, mas penso que não seria possível se ausentar completamente de algum tipo de situação problemática que emerge nas comunidades humanas em suas diversas camadas sociais. Este não seria o caso nem se esta situação estivesse geográfica ou socialmente distante, pois o outro sempre nos afeta de algum modo, ainda mais em tempos globalizados e sob os holofotes minuciosos da mídia 
virtual que se disseminam pelas redes sociais, nas quais os conteúdos informativos se espalham numa velocidade nunca vista em outros tempos, num jogo de "vale tudo". Verdade ou mentira, fake ou fato;

2. Temos também aquele grupo de pessoas que se compadecem, fazem discursos rebuscados e intermináveis nas plataformas digitais em apoio aos vitimados, passam até a impressão de que se colocam no lugar do outro, mas são incapazes de partir para uma ação mais concreta, dando a impressão de estarem impotentes diante do cenário de calamidade. O máximo que são capazes de fazer são discursos vazios e teorias sem ação, beirando a hipocrisia;

3. Há, ainda, os que fazem do caos, da dor do outro, do sofrimento coletivo, um trampolim de ascensão social e política. Dissimulam a compaixão em gestos caridosos para se autopromoverem diante do olhar do outro e serem admirados como 'cidadão de bem', ou mesmo para, simplesmente, se sentirem bem consigo mesmos ou com um deus que dizem acreditar, como numa espécie de moeda de troca para não serem condenados ao inferno ou merecerem algum tipo de recompensa ainda em vida. A exemplo disso, presenciamos corriqueiramente nas redes sociais, mas com mais frequência nesses últimos tempos, variadas manifestações de pessoas que se fotografam doando cestas básicas ou fazendo qualquer outro tipo de "caridade";

4. Por fim, existem, ainda, será que realmente existem? aqueles que de fato se colocam no lugar do outro, sofrem com o outro, tomam a dor do outro para si, e não conseguem ficar indiferentes ou apenas na teoria de uma suposta caridade que nunca é colocada em prática; aqueles que assumem a vida dolorida do outro para si e buscam soluções para o problema eminente, visando única e exclusivamente a libertação do outro que sofre, o alívio urgente do sofrimento que diretamente não lhes pertencem, mas têm plena consciência de seus respectivos comprometimentos para com o outro. E, o mais incrível, sem querer, absolutamente nada em troca, nem reconhecimento, nem gratidão, simplesmente exercem o gesto de compaixão pelo gesto em si, tendo como único objetivo o bem-estar daqueles e daquelas que se encontram em situação de risco e sofrimento. Ora, o questionamento que fica aqui é bem direto: atualmente, será possível esse tipo de ação compassiva? Essas práticas compassivas realmente existem para além dos interesses pessoais de quem as pratica, em dissonância com a indiferença em não enxergar a dor alheia como suas e com a ausência de empatia de se colocar no lugar daquele que está sofrendo por algum motivo? Ou ainda, seriam capazes de assumirem gestos de compaixão sem interesses pessoais à sombra de uma hipocrisia generalizada? 
Se assim o for, se de fato essas pessoas existem, espalhadas por esses grupos sociais, no exercício do olhar para o outro, elas exercem práticas de cuidado que vão além de si, despontando no cuidado do outro e com o outro, seja pela própria indiferença do olhar, pelo olhar compassivo, mas vazio de prática, seja pelo gesto puro de compaixão ou a compaixão dissimulada que visa apenas os próprios interesses. Seja como for, esse olhar para o outro nunca deixa de ser desafiador, pois sempre nos exige algum posicionamento, alguma postura, algum tipo de escolha, mesmo que seja a escolha de deixar sofrer, de deixar morrer. Afinal, em tempos obscuros como o que vivemos atualmente, nos quais a cegueira talvez fosse a melhor situação, pelo menos fingir cegueira diante da dor do outro nos traria em vão algum alívio de ópio, porque até podemos ignorar uma situação, mas deixar de olhá-la seria quase impossível. E esse deixar de olhar para o outro é ocupar-se em demasia com as próprias necessidades, quase que como um gesto narcisista e desesperado na urgência de ser e estar.

Mediante à rápida exposição apresentada, volto, agora, a atenção para Foucault e Nietzsche, buscando apoio teórico para pensar em um possível diagnóstico do presente. Num primeiro momento, quero tomar Foucault para pensar a compaixão na esteira dessa relação do sujeito consigo e com o outro, especificamente, em seu trabalho O governo de si e dos outros - A coragem da verdade, na aula do dia 21 de março, primeira hora, de 1984, ao fazer um retorno aos gregos e à filosofia helenística, quando Foucault (2011, p. 239) nos dirá que " $\mathrm{Na}$ filosofia antiga a vida soberana é em geral uma vida que tende à instauração de uma relação consigo". Ele não nos deixa esquecer, contudo, que, tanto para os gregos como para os helenísticos, o olhar para o outro e do outro é primordial na constituição de si, pois a vida voltada a si mesmo, autêntica e movida pela sabedoria, nos remete a uma relação com o outro.

O filósofo francês vai salientar ainda que

o outro aspecto igualmente importante no tema geral da vida soberana na antiguidade, é que a partir do momento em que e pelo próprio fato de que ela é relação consigo mesmo, a vida soberana também funda, ou se abre para, uma relação com o outro. (FOUCAULT, 2011, p.240).

Portanto, perceber o outro, sentir o outro, se voltar para o outro num gesto de cordialidade, de atenção, de cuidado, faz parte do movimento de ser soberano de si e, em vias de regra, estar para o outro, atento às suas necessidades enquanto sujeito que traz em si as necessidades básicas presentes também em nós como em todas as esferas da existência.

Num segundo momento da minha reflexão, quase que como um contraponto, se é que podemos ver por este prisma, Nietzsche, ao longo de suas reflexões sobre as relações humanas, sugere a compaixão, como um gesto egoísta do sujeito, que visa tão somente o próprio gozo, a partir de uma postura mais que soberana de si, culminando na prepotência e na arrogância em 
relação ao outro, dissimulando a própria impotência diante de sua condição humana e inacabada. O filósofo alemão, por sua vez, minimiza a relevância do que poderíamos denominar de responsabilidade do homem diante de si mesmo e do outro, ou seja, diante das fatalidades da vida. Conforme seu pensamento, o homem se vê despertado a tomar posse de si mesmo e de tudo que lhe diz respeito, mas sem a sombra da autopiedade, assumindo a posição de Übermensch, entendido, aqui, como um olhar para si à luz do niilismo, tomando a vida, de modo geral, como uma constante atitude de renovação e descoberta. Ou seja, diante das fatalidades da vida, o homem deve aprender a se reinventar sem sentir pena de si mesmo ou do outro, num falso moralismo piedoso, numa compaixão vazia de sentido e cheia de hipocrisia.

Portanto, é por meio desses dois filósofos, Foucault e Nietzsche, que pretendo refletir e, ao mesmo tempo sugerir pensar a compaixão nesses tempos de pandemia, sem ter a pretensão de trazer respostas prontas às urgências do momento, mesmo porque isso seria altamente complexo e acredito muito precoce, levando em consideração os tempos atuais. Meu objetivo é tão somente, tentar abrir uma possibilidade de reflexão a partir de um problema que acompanha a humanidade ao longo da história: sua relação consigo e com o outro em tempos em que a vida se torna ainda mais difícil, exigindo de cada homem uma resposta urgente, seja lá como ela for.

\section{DESENVOLVIMENTO}

\subsection{A perspectiva da compaixão no sujeito-outro em Foucault}

Para pensarmos sobre a compaixão à luz de Foucault, gostaria de propor um breve retorno à algumas questões levantadas pelo filósofo sobre um tema no qual ele dedicou considerável atenção: o sujeito. Afinal, ele próprio afirmou quando questionado sobre seu objeto de trabalho que "não é o poder, mas sim o sujeito que constitui o tema de minhas pesquisas." (FOUCAULT, 1995, p. 233). Visto que o sujeito e todas as suas nuances constitucionais é de suma importância para Foucault, gostaria de me ater no sujeito tomado como o outro, ou seja, o outro-sujeito, o sujeito-outro. Sempre que encontramos em seus textos referências ao sujeito, podemos considerar que estaremos diante de uma via de mão dupla que emerge a partir da relação com o outro, a saber, por exemplo, quando ele discute a questão do governo e do cuidado em seus cursos ministrados a partir de 1980.

Buscando refletir diretamente sobre o outro em sua constituição e em seu lugar, Foucault considera, de um lado, uma presença objetiva figurada no corpo como receptor das diversas sensações como dor e prazer; e, de outro, uma presença subjetiva na constituição de si, que vai além deste corpo e que está, também, susceptível às dores e aos prazeres. Foucault esclarece que 
Se podemos identificar facilmente na cultura moderna esse outro, cujo estatuto e cujas funções seria sem dúvida necessário analisar mais precisamente, esse outro indispensável para que eu possa dizer a verdade sobre mim mesmo, seja ele o médico, o psiquiatra, o psicólogo, o padre, em compensação na cultura antiga, em que no entanto sua presença é perfeitamente atestada, é preciso reconhecer que seu estatuto é muito mais variável, muito mais vago, muito menos nitidamente recortado e institucionalizado. Esse outro tão necessário para que eu possa dizer a verdade sobre mim mesmo, esse outro na cultura antiga pode ser um filósofo de profissão, mas também qualquer um. (FOUCAULT, p. 7, 2011).

Parece-me, dessa maneira, que não há como pensar o sujeito sem pensar o outro. Tanto para os antigos como para os modernos, como o próprio filósofo referencia, o outro é sempre um ponto de congruência e questionamento. Ainda que se mude o modo como se institui e se constitui, se desloca e se faz presente, o outro é sempre o meio pelo qual é possível ter acesso à verdade de si, e, pelo qual a compaixão pode emergir conforme sua necessidade. O outro é o canal para se encontrar a soberania de si. O que não se pode ignorar, em hipótese alguma, é que, quando se fala em sujeito, consequentemente ou mesmo, automaticamente, estaremos tomando o outro, pensando no outro e em todas as questões que isto envolve. O sujeito, portanto, não existe sem o outro, ele se constitui a partir do outro e vice-versa.

Ainda se faz necessário ressaltar que o filósofo não tocou diretamente no tema da compaixão propriamente dito. No entanto, a sugestão, aqui, é que partindo do que ele reflete sobre as relações dos sujeitos e seus processos de constituição, no que vai dedicar seu esforço para compreender os modos de governo e de cuidado, que busco respaldo teórico e metodológico para pensar nossa atualidade, em vista da pandemia, sob a perspectiva da compaixão. Parto precisamente da atenção que o Foucault dedica à filosofia helenística e seus recortes no interior do estoicismo e do pensamento grego, apresentado ao longo do cursos ministrados no Collège de France, tendo suas aulas reunidas na obra Hermenêtica do Sujeito, em 1981 e 1982 e A Coragem da Verdade, em 1983 e 1984, fazendo emergir um olhar específico em direção à constituição de um ethos pautado a partir de técnicas das quais o sujeito se vê sob o olhar do outro e atento aos seus direcionamentos.

Todas as afeições, apreços e desapreços que o sujeito pode vir a sentir em relação a si e ao outro passam pelo viés do entendimento do que é moralmente aprendido e ensinado nas relações estabelecidas entre os sujeitos no seio de suas comunidades, ou, como preferirem, usando o termo grego, no seio da polis. Seja a ira, o rancor, a vingança, a apatia ou mesmo sentimento benevolentes como o amor, a compaixão, a caridade e o respeito, em qualquer uma dessas situações, não há como escapar dos modos como os sujeitos se doam nas relações com o outro e vão se constituindo para si e para a sociedade. Porém, em situações caóticas, esses sentimentos afloram com mais intensidade e todos, sem exceção, são levados a tomar uma decisão, uma posição diante do outro ou dos outros. 
É nessa direção que pensar a compaixão como uma postura moral e ética, bem-vista e aceita socialmente, deixa o simples lugar de mais um sentimento que compõe a alma humana e passa a ser um posicionamento político. Dessa feita, podemos pensar com Foucault sobre o homem compassivo, como um homem, acima de tudo, político, a partir do que ele vai nos dizer na Hermenêutica do Sujeito, asseverando que para ser moralmente bom - e pensando, aqui, a compaixão como uma postura moral, portanto, para ser compassivo com alguém, é preciso voltar-se para dentro de si, é preciso cuidar de si. Apenas a partir dessa conversão a si que o homem será capaz de cuidar do outro, que terá condições de fato de sentir compaixão pelo outro, de se colocar no lugar do outro e assumir para si todas as dúvidas, medos, dores e anseios presente na vida que não lhe pertence diretamente, mas que não deixa de fazer parte de sua própria vida, uma vez que é a partir da relação com o outro que o indivíduo inicia seu processo de se constituir enquanto sujeito. A partir do outro, pois, a saber, mais especificamente, do outro mestre que orienta o discípulo no processo de conhecimento de si, de cuidado de si, que é possível esse deslocamento.

Daí Foucault vai nos dizer da importância desse gesto de retorno a si, tomando o ato de governar, pautado justamente pela capacidade de quem governa, de voltar-se para dentro de si, de cuidar de si, a fim de, somente assim, tornar-se soberano de si; e, posteriormente, ser capaz de se direcionar ao outro numa perspectiva autêntica de governo, de cuidado, com um gesto gratuito e genuíno de compaixão. Foucault vai nos dizer que

o homem moralmente bom é aquele que, uma vez por todas em sua vida, fixou para si um objetivo do qual não deve, de modo algum, desviar-se: não deve lançar seu olhar nem para a direita nem para a esquerda, nem para o comportamento dos homens, nem para as ciências inúteis, nem para todo um saber do mundo que para ele é sem importância; tampouco deve olhar para trás a fim de procurar atrás de si os fundamentos de sua ação. Os fundamentos de sua ação é que constituem seu objetivo. E o que é seu objetivo? É ele próprio. Portanto, é no cuidado de si, na relação de si para consigo enquanto relação de esforço em direção a si mesmo, que o imperador fará, não somente seu próprio bem, mas o bem dos outros. É cuidando de si que, necessariamente, cuidará (dos outros). (FOUCAULT, 2006, p. 248)

Verificamos que, partindo dessa ideia, a compaixão é um ato de cuidado e de governo que vai do si ao outro e do outro ao si, ou seja, uma relação de soberania no melhor sentido da palavra. Um olhar atencioso direcionado ao outro, no entanto, torna-se um gesto vazio se não segue as diretrizes sobre as quais Foucault nos alertou acima: que para se oferecer um cuidado justo, um governo justo, é necessário primeiro se cuidar, se governar. Caso contrário, a compaixão passaria a ser apenas um instrumento casual num jogo de interesses medíocres e dissimulados que manchariam as relações interpessoais e faria da sociedade um cenário apropriado para barganhas em uma rede de instrumentalização fria e calculista dos indivíduos, conforme os interesses de quem ocasionalmente se encontrasse numa condição econômica mais favorável. 
Não é novidade que a herança filosófica desenvolvida e reforçada pelos estoicos advém dos gregos. Foucault a menciona e a introduz em suas reflexões a respeito da relação de Sócrates e o jovem Alcebíades na primeira e segunda hora das aulas de 6 de janeiro de 1982, do curso $A$ hermenêutica do sujeito, na qual a relação interpessoal multifacetada é primordial no conhecimento de si e do outro. Para tanto, além dos estoicos, tomarei também os gregos para ajudar a pensar um pouco sobre essa relação do sujeito consigo e com o outro, levando as reflexões sempre de modo a pensar a questão da compaixão, principalmente, como um gesto político.

Se ter compaixão é ter um olhar político, um posicionamento político dentro da sociedade, trata-se, então, de assumir um lugar diante do olhar do outro com todos os seus desafios e circunstâncias que podem advir. Em que isso tocaria, portanto, na postura compassiva dos sujeitos em suas relações? Mais especificamente, como o cuidado de si e do outro, o conhecimento de si, a partir do outro, e o governo de si e do outro, enfim, a soberania de si, estão conectados à compaixão?

Considerando essa perspectiva e seus questionamentos, entendemos a coexistência dos domínios das relações interpessoais e da política, ao nos debruçarmos sobre a discussão de Foucault, na referida aula, em que apresenta a principal razão pela qual Alcebíades procurou Sócrates. O jovem grego foi motivado pelo seu desejo de querer governar a polis. Sendo assim, o filósofo grego, em contrapartida, chamou a atenção do jovem para o fato de que o pressuposto para se governar bem uma cidade, ou seja, para ser um bom governador, para governar o outro, para ser soberano do outro, e, aqui, podemos pensar no sentido de prestar serviço à comunidade, de ser compassivo e atento às necessidades de quem surge frente aos nossos olhos, é antes de tudo pautado pelo fato de saber governar bem a si mesmo, de cuidar de si, é antes ser soberano de si.

Mas como governar a si mesmo? Como cuidar corretamente de si? Como ser soberano de si? Exatamente este é o ponto pelo qual Sócrates inicia todo processo de ensinamento do jovem Alcebíades, convidando-o primeiramente a conhecer-se a si mesmo. É justamente para isso que Foucault vai nos chamar a atenção:

\footnotetext{
vemos que a necessidade de ocupar-se consigo eclode como uma urgência, não no momento do texto em que Alcibíades formula seus projetos políticos, mas quando se apercebe que ignora ... ignora o quê? Pois bem, ignora o próprio objeto, a natureza do objeto com que tem que ocupar-se. A necessidade de ocupar-se consigo coloca a seguinte questão: qual é pois o eu de que é preciso cuidar quando se diz que é preciso cuidar de si? (FOUCAULT, 2006, p. 49).
}

A maior dificuldade do jovem Alcebíades era identificar no que e a quem deveria dedicar atenção. Seu foco estava totalmente direcionado às questões relacionadas ao poder, ao ato de governar em si e ignorava completamente que, para além de governar a vida alheia, era necessário aprender a governar a própria. Antes de querer ser visto como soberano do outro, teria que aprender a ser soberano de si, para não arriscar a sua vida a se tornar um gesto vazio de sentido e 
fadado a equívocos. Neste ato de governar e de cuidar estão inclusos o gesto compassivo, a autêntica compaixão para com o outro, desprovida de interesses pessoais e alimentada pelo objetivo de querer oferecer ao outro o melhor de si e atendê-lo com urgência em sua real necessidade, seja física, seja psíquica.

O que chama atenção, e que encontraremos vivamente na stoá, é que não seria suficiente apenas o movimento de se conhecer, como era a principal meta para os gregos, visando o governo da cidade e a manutenção de um poder benéfico sobre os outros. Mais que isto, e antes disto, porém, os estoicos reconheceram que era necessário que o jovem aplicasse a si mudanças de posturas e de perspectivas perante a si mesmo e ao outro. Não só o jovem, é claro, mas em âmbito geral todo indivíduo que quisesse e se propusesse a submeter-se a essa empreitada. Seria mister, portanto, que o sujeito se preocupasse antes de tudo, em cuidar de si, se refazendo em seu próprio ethos, deixando maus costumes e vícios para trás e assumindo a temperança e a moderação em todos os seus atos e palavras. Não que os gregos também não se importassem com isso, mas o foco deles estava sobre o ato de governar em si. Já para os estoicos, Foucault entende que

cuidar de si deve ser a tarefa de toda uma vida, o objetivo não é mais de preparar-se para
a vida adulta ou para uma outra vida, mas de prepara-se para uma realização total: a vida.
Essa realização torna-se total no instante que precede à morte. Essa idéia de uma
proximidade feliz da morte - a velhice como completude - constitui uma inversão de
valores que se ligam tradicionalmente à juventude entre os gregos. (FOUCAULT, 1982,
p. 10).

Observamos que Foucault chama a atenção para o fato de que no estoicismo a preocupação se amplia, ultrapassa os muros da polis e os limites de idade. O cuidado de si, o governo de si, torna-se um movimento que atinge o sujeito em toda a sua plenitude e, ao mesmo tempo, em todas as suas limitações. Exatamente é neste ponto que a compaixão se torna fator relevante, visto que para poder ter compaixão do outro, é preciso ter compaixão de si. Ter um olhar compassivo para si é perceber as próprias limitações e ir buscar os meios corretos para minimizar ou mesmo sanar a falta, a necessidade. Nesse viés, se somos capazes de ter esse olhar delicado para conosco, também saberemos direcioná-lo ao outro e oferecer-lhe opções de melhorias naquilo que lhe falta.

Tanto no contexto grego quanto no helenístico, o lugar do outro que orienta as práticas de si passa por algum tipo de motivação, seja exclusivamente política, delineada por um jogo de poder, seja pelo fato de considerar fazer o bem, em proporcionar ao outro a oportunidade de se constituir e evoluir enquanto sujeito, tendo um olhar compassivo para o outro. Enfim, isso de acreditar que se está fazendo o bem e de ser soberano de si atravessa o viés da compaixão, se pensarmos como um movimento de se colocar no lugar do outro e considerar que se gostaria que fizesse o mesmo para si. O dizer e, ao mesmo tempo, o ouvir aquilo que deve ser feito, como deve ser feito e em 
que momento deve ser feito está alicerçado pelo saber e pelo exemplo de vida dado a partir deste saber, que vai além de interesses de poder e de manejos políticos.

Seguindo essa linha de reflexão, poderíamos, então, considerar o filósofo como aquele capaz de propagar o saber. Este saber, por sua vez, é que lhe dá condições para ser visto pelos demais como um sujeito que governa a si mesmo, sendo capaz de mostrar o caminho rumo ao conhecimento de si, assim como apresentar os métodos e as técnicas tão caros capazes de fazer de um sujeito comum, submetido a seus desejos físicos e psíquicos, aos vícios mais cotidianos, aos anseios e inseguranças produzidos no meio em que convive, tomar a direção da própria vida. Chegando a isso, o sujeito poderá, a partir do aprendizado e das práticas dessas técnicas, ensinadas pelo filósofo, governar a si mesmo com altivez e sucesso. Talvez aí estaria a verdadeira compaixão pelo outro: oferecer-lhe a oportunidade de se governar e não ser alienadamente governado pelos outros, quando seria apenas mais uma peça de manobra num jogo muitas vezes de submissão do sujeito.

\subsection{A compaixão em Nietzsche}

Pensar a compaixão a partir de Nietzsche não poderia ser diferente do padrão que segue seu pensamento inquieto, desafiador e questionador, ao ponto de sermos quase que levados a despila de todas as indumentárias benéficas e despretensiosas que se serviu ao longo da história, representando sempre o lado mais nobre e ético dos homens. Nietzsche não cede aos encantos dos gestos compassivos dos homens, ele vai além do que está por trás do simples ato de doação e generosidade que supostamente os homens demonstram uns pelos outros em momentos difíceis da vida.

O filósofo alemão enxerga, sim, por trás da compaixão, mais uma das facetas de um jogo de poder dissimulado, uma farsa equivocada e débil, capaz de levar multidões a acreditar que, de fato, a compaixão é capaz de redimir o homem de sua perversidade e permitir a salvação de muitos diante de um perigo que afeta a própria dignidade humana, elencando, de um lado, um herói, um super-homem, como o filósofo mesmo vai denominar, e, do outro, o fraco, o frágil, necessitado de salvação.

Porém, o super-homem ao qual Nietzsche se refere como verdadeiro e autêntico é aquele que ele apresenta e, conforme suas próprias palavras, ensina

Eu vos ensino o super-homem. O homem é algo que deve ser superado. Que fizestes para superá-lo? [...] Que é o macaco para o homem? Uma risada, ou dolorosa vergonha. Exatamente isso deve o homem ser para o super-homem: uma risada, ou dolorosa vergonha [...] vede, eu vos ensino o super-homem! O super-homem é o sentido da terra. Que a vossa vontade diga: o super-homem seja o sentido da terra! (NIETZSCHE, 2011, p. 13-14). 
Basicamente, não é o homem compassivo ou o homem sofredor que leva a credibilidade do filósofo, contrariamente, o super-homem considerado por ele é aquele que se alinha às vontades da terra; ou seja, se posiciona harmoniosamente conforme a natureza, o universo, e desta maneira está acima das fatalidades do cotidiano. Neste viés, aos olhos de Nietzsche, ao atender o outro que se encontra em situação de risco, o sujeito que o faz, consciente ou inconscientemente (não há como fugir dessa condição), busca apenas responder e saciar seu desejo de se sentir bem, de se sentir útil, de se sentir como uma pessoa boa. Busca tão somente, por mais que negue e que levante a bandeira do 'bom samaritano', o prazer que pode obter socorrendo alguém que se encontra em perigo e assumir, daí, o papel de salvador, daquele que traz o alívio à dor alheia, tornando-se aos olhos dos outros o grande salvador. E, por tal motivo, é digno das regalias que são próprias de um herói, massageando seu ego e nutrindo seu narciso de estimação.

Tendo em vista o cenário em que vivemos atualmente de pandemia, essa proposta nietzschiana de pensar a compaixão por esse viés faria sentido? Como já foi apontado na introdução, existem pessoas que usam dessas situações caóticas, da miséria alheia, para se auto promoverem, para se sentirem bem consigo mesmas e para serem vistas como o herói ideal em tempos de crise. Mas será que de fato não seria possível admitir um gesto puramente compassivo, um olhar para a dor do outro sem qualquer tipo de interesse pessoal e o conceito de super-homem do qual se nutre o filósofo não estaria equivocado e restrito demais à sua filosofia?

São essas questões que gostaria de reforçar e desenvolver um pouco mais, sem a intenção de respondê-las, buscando somente trazê-las à tona e esboçá-las. Desejo, assim, apenas introduzir, pensar e questionar, o que é a compaixão de fato e se realmente é possível ser compassivo sem segundas intensões, se seria a única saída para amenizar a dor que sobressalta a vida, ou, ainda, se não há como fugir da batida seca e impiedosa do martelo de Nietzsche, que a conceitua apenas como um gesto egoísta como tantos outros. Para o filósofo, essa relação medíocre do homem sofredor e do homem salvador é ultrapassada e limitada, fazendo reverberar sentimentos negativos como a inveja, o orgulho, o medo e a alienação.

Para além de fingir responsabilidade pelo outro, ou se sentir culpado por alguma desgraça que acontece, Nietzsche propõe uma aceitação das fatalidades da vida, pois diante delas não se tem muito a fazer que não seja assumir-se em sua própria existência, lançando fora todo sentimento de culpa e medo. Se estamos fadados, como ele afirma, ao eterno retorno ao mesmo, ao passado que se repete no presente, a ousadia proposta pelo filósofo é despertar o homem para se lançar no futuro, desejar o futuro, assumindo-se como Ubermensch. Ou seja, cabe-nos aceitar o sentido da própria vida que corresponde exatamente à condição niilista, extinguindo o lugar de um super- 
herói, de um super-homem, desmitificando a estruturação de uma fé devotada a um deus, tomando as rédeas da própria vida num movimento criativo e constante.

Em seus apontamentos, faz-se necessário destacar que o meio pelo qual o homem conseguirá se tornar um super-homem à moda nietzschiana é através do conhecimento. Não é pela religião, pela fé e pelas manipulações políticas que o sujeito se tornará senhor de si, como sugere Nietzsche. Diferentemente, é por meio da coragem de conhecer o mundo à sua volta e, principalmente, de se conhecer, que o homem será capaz de ter uma relação de maturidade com o sofrimento e com a dor, não esperando a salvação de fora, sendo, então, seu próprio artífice, não fazendo da vida um fardo pesado e insuportável.

A proposta de Nietzsche é mudar o olhar, o foco do olhar. É ter uma visão mais ampla em relação à vida e aos seus acontecimentos, não se limitar e se fechar às fatalidades do cotidiano. Restaria, outrossim, ao homem devotar o que ele chama de amor à terra. Compreendemos aqui a relação do homem num sentido mais universal consigo e com o mundo, aceitando seu lugar enquanto ser vivo ausente de uma crença a um deus formatado pelos próprios homens. Seria exatamente ter a ousadia e a coragem de se despir de toda doutrinação alienada e aprendida ao longo da história, que, sorrateiramente, subjuga o indivíduo a conceitos tacanhos, a fim de se lançar destemidamente rumo ao futuro, desvencilhando-se dessas correntes ideológicas que querem por grilhões com pesadas pedras de culpa nos tornozelos de toda humanidade, para que, assim, seja mais fácil dominar, controlar e manter o poder sobre os outros, preservando essa estrutura doentia de sociedade que se mantém até hoje.

Segundo o filósofo alemão, a compaixão não passa de mais uma artimanha nesse jogo sujo, não passa de uma armadilha engenhosa que engana e dissimula suas verdadeiras intenções, que são basicamente a autopromoção de quem oferece compaixão e do vitimismo por parte de quem a recebe. Isso faz emergir uma relação doentia, cheia de vícios e mentiras, fazendo emergir, de um lado, o herói que salva e, do outro, a vítima indefesa, carente, sentindo prazer em depender dos atributos e do socorro heroico de um salvador. Ora, essa rede que se estabelece no seio da sociedade ocidental é terrivelmente abominável e desprezível aos olhos de Nietzsche, já que ele a enxerga como uma trama perigosa e suja. Sua proposta é justamente diversa. É cada homem assumir as rédeas da própria vida e se tornar responsável por todos os seus atos, sem a pretensão de ser herói e muito menos a dissimulação em ser vítima.

É preciso deixar claro que o conceito de compaixão e amor, aos quais se refere Nietzsche, estão muito mais ligados à ideia de um processo contínuo de mudança e evolução que fazem parte do universo, no sentido de movimento. Não se prender, e não se deixar prender, mas continuar seguindo em frente se aproximando do todo universal, acompanhando e se movimentando 
juntamente com a terra, eis a proposta do filósofo. Fornazari esclarece que este sentimento de amor e compaixão vislumbrado no pensamento nietzschiano está ligado a

liberar a vida e o pensamento das amarras do Mesmo e do Idêntico e de tudo aquilo que é responsável por uma conservação. Pois o mesmo não retorna porque carece de poder de metamorfose, restando-lhe o recurso de negar a diferença, implicando ao mesmo tempo a criação do novo e a recriação constante de si mesmo. (FORNAZARI, 2006, p. 30).

É preciso coragem para mudar, é preciso ousadia para enfrentar as condições impostas. São as características primordiais do pensamento de Nietzsche: ter a coragem de romper com o círculo vicioso ao qual as religiões submeteram a humanidade, especialmente, o cristianismo, e, livremente, se lançar para dentro da própria existência, para dentro de si, para dentro da própria vida. Se lançar rumo ao novo que sempre se renova, sempre se atualiza. E isso, de não parar, é para muitos, assustador e inaceitável, pois a maioria prefere a comodidade da sombra de um salvador e transferir para ele toda responsabilidade das decisões de sua própria vida.

Em suma, a proposta que encontramos no pensamento de Nietzsche, ao nos deparamos com situações trágicas como essa em que vivemos em 2020, vai na contramão dos discursos que normalmente se aplicam pela grande maioria das pessoas. A compaixão, a caridade, de um lado, a lamentação, a insistência na lamúria, de outro, são vistos aos olhos do filósofo alemão como uma hipocrisia degenerada que propicia um círculo vicioso sem o mínimo de colaboração positiva para a evolução da humanidade. Para Nietzsche é inútil lamentar, para ele é inútil a compaixão, e, no lugar desses posicionamentos normalmente esperados, propõe agir-se com leveza, com coragem e mais ainda, com um certo desprezo ao que pode parecer eficaz às dores sofridas e sentidas a nível individual e coletivo.

\section{CONCLUSÃO}

Caminhando para o fim deste trabalho, gostaria de compartilhar as inquietudes e questões que surgiram no decorrer dessas linhas e que ficarão como proposta para se pensar e refletir sobre esses últimos tempos de crise, atípica, pois, até então, não havíamos vivido, um período longo de quarentena, causada por uma pandemia de um vírus letal. Afinal, a princípio, o que todos desejam é não perder o controle da situação, é não se perder no descontrole alheio e próprio. A princípio, vamos na direção de um monitoramento que desemboca na limitação da liberdade, de uma suposta liberdade que julgamos ter, que nos permite ir e vir, que nos permite frequentar lugares que selecionamos, que nos permite ser um cidadão tipicamente possuidor de todos os seus direitos.

Em contrapartida, diante de um passo dado, inusitado, que nos empurra pra uma realidade impensável e que só conhecíamos em filmes apocalípticos, compreendemos que nossa existência não passa de uma frágil ilusão, que nosso lugar em nós mesmos, no mundo, seja social seja natural, 
não passa de um lugar efêmero. Entendemos que o fato de estarmos presentes não significa muita coisa além de simplesmente estarmos superficialmente e passageiramente na vida. O desafio de tomar dois grandes pensadores, tendo ao mesmo tempo a sorte de tê-los como base teórica para navegar em águas tão turvas e agitadas como nossa atualidade, passa a ser, na verdade, o grande sentido da filosofia, que é fazer pensar a atualidade a partir de reflexões consolidadas, sem se fechar em seus próprios conceitos, abrindo efetivamente novos caminhos, novas propostas para se pensar o sujeito em todas as suas esferas, simultaneamente social e existencial.

Por fim, deixo as seguintes problematizações: será, então, que existir ultrapassa nossa simplória capacidade de ter a consciência de que existimos? Será que, mesmo em tempos de pandemia, o melhor caminho é o da compaixão, o melhor lugar é o da compaixão, o melhor gesto é o da compaixão, supostamente tão onipresente quanto o vírus, tão poderosa quanto o vírus e tão imortal quanto o vírus? Se assim realmente o for, talvez possamos pensar em despertar a compaixão autêntica em nós mesmos nesses tempos difíceis. E talvez a existência se torne mais suave nesses tempos em que a leveza pesa tanto quanto um vírus e, assim, nos propõem sermos mais soberanos de si e menos arrogantes e prepotentes.

\section{REFERÊNCIAS}

FORNAZARI, Sandro Kobol. A diferença e o eterno retorno. Cadernos Nietzsche, São Paulo, n. 20, p. 19-33, 2006.

FOUCAULT, Michel. A Hermenêutica do Sujeito. São Paulo: Martins Fontes, 2006.

FOUCAULT, Michel. A coragem da verdade. O governo de si e dos outros, São Paulo: Martins Fontes, 2011.

FOUCAULT, Michel O Sujeito e o Poder. In: Foucault: uma trajetória filosófica. DREYFUSS, Hubert. L., RABINOW, Paul. Rio de Janeiro, RJ: Forense Universitário, 1995. p. 231-249.

FOUCAULT, Michel. Technologies of the self (Université du Vermont, outubro, 1982; trad. F. Durant Bogaert). In: Hutton (P.H.), Gutman (H.) e Martin (L.H.), ed. Technologies of the Self. A Seminar with Michel Foucault. Anherst: The University of Massachusetts Press, 1988, pp. 16-49. Traduzido a partir de FOUCAULT, Michel. Dits et écrits. Paris: Gallimard, 1994, Vol. IV, pp. 783813 , por Karla Neves e wanderson flor do nascimento.

NIETZSCHE, Friedrich. Assim falou Zaratustra: um livro para todos e para ninguém. Trad. de Paulo César de Souza. São Paulo: Companhia das Letras, 2011. 